\title{
A Comparative Study between Nifedipine, Ritodrine and Magnesium Sulfate as Tocolytics in Cases of Preterm Labor and Their Effect on Utero Placental Perfusion Asem A. Abdo Mousa ${ }^{1}$, Mohamed A. Mohamed ${ }^{1}$, Mohamed S. Radwan ${ }^{2}$, Khaled F. El Sayed ${ }^{1 *}$ \\ Departments of ${ }^{1}$ Obstetrics and Gynecology, Faculty of Medicine, Al-Azhar University; ${ }^{2}$ Clinical Pathology Faculty of Medicine, Al-Azhar University; Faculty of Medicine, Al-Fayoum University \\ *Corresponding author: Khaled F. El Sayed; Mobile: 011140254235, Email: tantawy_wael@yahoo.com
}

\begin{abstract}
Background: in the developed world, preterm birth (PTB) is a major problem in modern obstetrics; its prevalence is still rising in many industrialized countries. Early PTB (before 34 weeks) is particularly associated with high rates of mortality and morbidity.

Aim of the Work: to compare the efficacy of oral nifedipine, intra venous ritodrine and magnesium sulfate as tocolytics in cases with preterm labor and evaluate their effects on the utero placental perfusion in order to choose the safest and most cost-effective drug.

Patients and Methods: a prospective study that was conducted in El sayed Galal and El Hussien University hospitals from November 2016 to November 2018. By identifying 150 pregnant women with gestational age from 24-37 weeks gestation with preterm labour pain, intact membranes, singleton pregnancy.

Results: a statistically significant difference was found between groups according to fetal umbilical artery PI before and after treatment. Also, significant difference between before and after treatment according to fetal umbilical artery PI in magnesium sulfate group. Also a statistically significant difference between groups according to fetal middle cerebral artery PI before and after treatment. Also, significant difference between before and after treatment according to fetal middle cerebral artery PI in nifedipine and magnesium sulfate group.

Conclusion: there was no overall difference between nifedipine, magnesium sulfate and ritodrine, in their efficacy as tocolytic for preterm labor. However, Nifedipine had fewer maternal side effects followed by magnesium sulfate than ritodrine. Irrespective of their tocolytic effects, magnesium sulfate has the most significant effect on Doppler study.
\end{abstract}

Keywords: Nifedipine, Ritodrine, Magnesium sulfate, Tocolytics, Preterm labor, Utero placental perfusion.

\section{INTRODUCTION}

Premature birth remains the leading cause of premature death. Preterm infants, known as labor before 37 weeks of gestation, often suffer from a large immediate morbidity and need prolonged stay in neonatal intensive care units with a high risk of longterm neurological disease in a proportion of survivors. Early in preterm labor, the risk increases especially when labor occurs before 32 weeks ${ }^{(1)}$.

Worldwide, around 15 million children were born preterm in 2010 which represents around $11 \%$ of live births. Around $85 \%$ of the children born before 37 weeks of gestation can be considered to be moderately or late preterm births (32-36 weeks), 10\% very preterm (28-31 weeks), and 5\% extremely preterm (before 28 weeks) ${ }^{(2)}$.

Numerous factors that can be identified during the periconceptional period are associated with the risk of preterm delivery. There are many maternal or fetal characteristics that have been associated with preterm birth, including maternal demographic characteristics, nutritional status, pregnancy history, present pregnancy characteristics, psychological characteristics, adverse behavior's, infection, uterine contractions and cervical length, and biological and genetic markers ${ }^{(3)}$.

As a result clinicians use tocolytics for pregnancy prolongation for 48-hours to permit the administration of corticosteroids to enhance fetal lung maturity and reduce neonatal morbidity and mortality ${ }^{(4)}$.

There is considerable variation in the type of tocolytic agent used in different parts of the world. Magnesium sulphate has been widely used as a tocolytic in the United States of America (5).

Magnesium sulphate can be used as a tocolytic and also in the management of pre- eclampsia, eclampsia and neuroprotective for neonates ${ }^{(6)}$.

The precise mechanism by which magnesium sulfate exerts a neuroptective benefit is not known, but it is speculated that it possess anti-inflammatory and anti-excitotoxic effects while also improving cerebral blood flow and stabilizing fluctuations in blood pressure in the newborn infant ${ }^{(7)}$.

Reported side effects of magnesium sulphate include maternal side effects as flushing, sweating, sensation of warmth, nausea, vomiting, headache, palpitations and rarely pulmonary edema. Administration of a concentration above the recommended therapeutic range can lead to respiratory depression, respiratory arrest and cardiac arrest ${ }^{(\mathbf{8})}$.

Neonatal side effects include hypermagnesaemia, hyporeflexia, poor sucking, and, rarely, respiratory depression needing mechanical ventilation ${ }^{(9)}$.

To assess the fetal circulation Doppler sonography is used to provide valuable information regarding neonatal prognosis and fetal well-being in 
compromised pregnancies. Doppler sonography has been used for evaluation of effect various drugs on Doppler blood waveforms ${ }^{(\mathbf{1 0})}$.

In pregnancy, umbilical artery (UA), uterine artery (UtA) and fetal middle cerebral artery (MCA) Doppler parameters can be assessed carefully improving detection of disturbances in fetus wellbeing ${ }^{(11)}$.

The ratio of middle cerebral artery to umbilical artery $(\mathrm{MCA} / \mathrm{U})$ can be used as a good indicator of fetal prognosis and fetal well-being ${ }^{(\mathbf{1 2})}$.

The great incidence of usually mild but potentially severe side effects of beta- sympathomimetics has led to the search for better drugs. Nifedipine is a calcium channel blocker drug which reduces the amplitude and the frequency of contractions and the basal myometrial tone and is more active in pregnant than in non pregnant women. Many randomized controlled trials compared its efficacy with ritodrine and most of them found that nifedipine is more effective than ritodrine in prolonging pregnancy beyond 7 days and much less likely to cause maternal side effect ${ }^{(\mathbf{1 3})}$.

\section{AIM OF THE WORK}

To assess the effect of oral Nifedipine, intravenous ritodrine and magnesium Sulfate as tocolytics agents in pregnant women with threatened preterm labour and to evaluate their effects on the utero placental perfusion in order to choose the safest and the most effective drug.

\section{PATIENTS AND METHODS}

This prospective case study was held in the period from November 2016 till November 2018 on 150 patients attended and admitted from the casualty unit of the Obstetric department in El Sayed Galal and El Hussien University Hospitals with preterm labor pains, intact membranes, singleton pregnancy between 24 and 37 weeks gestation which were divided into three groups and assigned for the following drugs:

Group A: 50 patients received oral Nifedipine.

Group B: 50 patients received intravenous ritodrine.

Group C: 50 patients received intravenous magnesium sulfate.

To fulfill the estimated number of patients for this study (150 patients), we actually studied 177 patients who reached 150 patients due to drop out and non compliance of many patients; 8 in the Nifedipine group, 9 in the ritodine group and 10 in the magnesium sulfate group. The study was approved by the Ethics Board of Al-Azhar University and an informed written consent was taken from each participant in the study.

\section{Regimens of administration of tocolytics:}

Group A: 50 women received Nifedipone (epilate retard, Eipico pharmaceutics) orally in the form of initial loading dose $30 \mathrm{mg}$ and maintenance oral 20 $\mathrm{mg} / 6$ hours and if contraction relapsed after their suppression before discontinuation of treatment an extra dose of $10 \mathrm{mg}$ of oral Nifedipine was added.
Group B: 50 women received $\mathrm{B}_{2}$ adrenergic receptor agonist ritodrine (Yotopar 12, duphar pharmaceutics) lamp $=50 \mathrm{mg}$ one ampoule dissolved in dextrose $5 \%$ solution and given by $50 \mu \mathrm{g} /$ minute maternal heart rate should not exceed 120 beats/minute the dose increased by $50 \mu \mathrm{g} /$ every 20 minutes intervals until contractions stopped or unacceptable side effects occurred the lowest effective dose was maintained for 24 hours after cessation of contractions the maximum recommended dose was $350 \mu \mathrm{sg} /$ minute.

Group C: 50 women received magnesium sulfate (Magnesium sulfate Eipico pharmaceutics) lamp $=1$ gm by intravenous infusion started with initial dose of 6 gm over 20 minutes followed by a maintenance dose $2 \mathrm{gm} /$ hour initially we added 6 amp of magnesium sulfate to $250 \mathrm{ml}$ of lactated ringer and given by intravenous infusion over 20 minutes then we added 8 amp to $250 \mathrm{ml}$ of lactated ringer and given by intravenous infusion over 4 hours treatment continued for 24 hours after cessation of contractions.

The drug discontinued if respiratory rate less than 12 /minute, less of knee jerk or urine out put less than $100 \mathrm{ml} / 4$ hours.

The study protocol was approved by the Ethics and Research Committee in El Sayed Galal and El Hussien University Hospitals.

\section{Inclusion criteria:}

The study included patients with gestational age between (24-37) weeks, singleton pregnancy, painful, regular uterine contractions more than two every ten minutes for more than one hour with cervical changes, Cervical dilatation more than $1 \mathrm{~cm}$ and less than $3 \mathrm{~cm}$, intact membranes and no medical disorders contraindicating tocolytics.

\section{Exclusion criteria:}

Patients with cervical dilatation $>3 \mathrm{~cm}$, Hypotension (less than $80 \mathrm{mmHg}$ systolic or $50 \mathrm{mmHg}$ diastolic), Major fetal congenital anomalies, unreassuring traces of fetal cardiotocography, antepartum hemorrhage or history of recurrent vaginal bleeding, Rupture of membranes, multiple pregnancy, poly-hydraminos, chorioamnionitis, Unexplained pyrexia, medical disorders i.e. diabetes, cardiac disease, Non steroidal antiinflammatory drug therapy and other tocolytic therapy during this pregnancy were excluded from the study.

\section{All patients were subjected to:}

1- Verbal consent.

2- History taking

3- General and abdominal examination was done

4- Pelvic examination:

To assess the state of membranes and exclude their rupture through examination with a sterile Cusco speculum, to exclude vaginal bleeding and assess the state of the cervix and measure the bishop score. Bishop score was reassessed after cessation of contractions and 24 hours later.

5- Sonographic assessment: 
To estimate the gestational age, amount of liquor and to exclude placenta previa, placental abruption and major fetal congenital anomalies. Several ultrasound parameters were used to estimate gestational age including biparietal diameter (BPD), head circumference (HC), and femur length (FL). Electronic monitoring of uterine contractions and fetal heart rate until the uterine contractions disappeared. Afterwards, fetal heart rate and uterine contractions were monitored for 1 hour every 12 hours during hospital admission.

6- Laboratory Investigations including complete blood picture, Liver function tests, Kidney function tests, fasting and postprandial blood glucose level, complete urine analysis and high vaginal swab.

Uterine contractions were measured by placing the transducer on the abdomen close to the fundus. The transducer was held against the abdominal wall, and as the uterus contracted, a measurable electric signal that indicated the relative intensity of the contraction was recorded.

Fetal heart rate was recorded by another transducer placed at the point of maximum intensity of the fetal heart sound which was related to the fetal presentation and position.

The primary outcome was prolongation of gestation expressed as percentage of the time from entry to 37 weeks. Secondary outcomes were the proportion of women who delivered the same day, next day, within 7 and 14 days of entry and by 32, 34 and 37 weeks.

\section{Statistical analysis}

Recorded data were analyzed using the statistical package for social sciences, version 20.0 (SPSS Inc., Chicago, Illinois, USA). Quantitative data were expressed as mean \pm standard deviation (SD). Qualitative data were expressed as frequency and percentage.

\section{The following tests were done:}

A one-way analysis of variance (ANOVA) when comparing between more than two means.

Post Hoc test: Least Significant Difference (LSD) was used for multiple comparisons between different variables.

Chi-square $\left(\chi^{2}\right)$ test of significance was used in order to compare proportions between qualitative parameters.

The confidence interval was set to $95 \%$ and the margin of error accepted was set to $5 \%$. So, the pvalue was considered significant as the following:

Probability (P-value):

- P-value $<0.05$ was considered significant.

- P-value $<0.001$ was considered as highly significant.

- P-value $>0.05$ was considered insignificant.

\section{RESULTS}

Table (1): Comparison between groups according to demographic data

\begin{tabular}{|c|c|c|c|c|c|}
\hline Demographic data & $\begin{array}{c}\text { Nifedipine } \\
(n=50)\end{array}$ & \begin{tabular}{|c|} 
Magnesium \\
sulfate $(n=50)$
\end{tabular} & $\begin{array}{c}\text { Ritodrine } \\
(\mathrm{n}=50)\end{array}$ & ANOVA & p-value \\
\hline $\begin{array}{l}\text { Age (years): } \\
\text { Range } \\
\text { Mean } \pm \text { SD }\end{array}$ & $\begin{array}{c}17-38 \\
26.44 \pm 5.43\end{array}$ & $\begin{array}{c}19-40 \\
26.75 \pm 4.24\end{array}$ & $\begin{array}{c}18-37 \\
27.81 \pm 6.47\end{array}$ & 1.533 & 0.223 \\
\hline $\begin{array}{l}\text { Parity } \\
\text { Range } \\
\text { Mean } \pm \text { SD }\end{array}$ & $\begin{array}{c}0-4 \\
1.79 \pm 1.14\end{array}$ & $\begin{array}{c}0-3 \\
2.01 \pm 0.87\end{array}$ & $\begin{array}{c}0-4 \\
1.69 \pm 0.65\end{array}$ & 1.684 & 0.421 \\
\hline $\begin{array}{l}\text { Previous preterm labor } \\
\text { Range } \\
\text { Mean } \pm \text { SD }\end{array}$ & $\begin{array}{c}0-3 \\
0.66 \pm 0.81 \\
\end{array}$ & $\begin{array}{c}0-2 \\
0.74 \pm 0.68\end{array}$ & $\begin{array}{c}0-2 \\
0.53 \pm 0.64 \\
\end{array}$ & 0.87 & 0.126 \\
\hline $\begin{array}{l}\text { Gestational age on admission } \\
\text { Range } \\
\text { Mean } \pm \text { SD }\end{array}$ & $\begin{array}{c}25-35 \\
31.96 \pm 1.52\end{array}$ & $\begin{array}{c}25-37 \\
32.06 \pm 1.64\end{array}$ & $\begin{array}{c}26-36 \\
31.9 \pm 1.68\end{array}$ & 1.454 & 0.211 \\
\hline $\begin{array}{l}\text { Mode of delivery } \\
\text { VD } \\
\text { CS }\end{array}$ & $\begin{array}{l}10(20 \%) \\
40(80 \%)\end{array}$ & $\begin{array}{c}8(16 \%) \\
42(84 \%)\end{array}$ & $\begin{array}{l}11(22 \%) \\
39(78 \%)\end{array}$ & 3.761 & 0.291 \\
\hline $\begin{array}{l}\text { Apgar score } \\
\text { Range } \\
\text { Mean } \pm \text { SD } \\
\end{array}$ & $\begin{array}{c}3-6 \\
4.56 \pm 0.64 \\
\end{array}$ & $\begin{array}{c}3-5 \\
4.43 \pm 0.62 \\
\end{array}$ & $\begin{array}{c}3-7 \\
4.14 \pm 0.58 \\
\end{array}$ & 0.957 & 0.139 \\
\hline $\begin{array}{l}\text { Birth weight in grams } \\
\text { Range } \\
\text { Mean } \pm \text { SD }\end{array}$ & $\begin{array}{c}850-3100 \\
1783.9 \pm 237.1 \\
\end{array}$ & $\begin{array}{c}900-3250 \\
1718.5 \pm 245.9\end{array}$ & $\begin{array}{c}950-3050 \\
1650.9 \pm 254.8\end{array}$ & 1.0527 & 0.1529 \\
\hline
\end{tabular}

Table (1) shows no statistically significant difference between groups according to demographic data. 
A Comparative Study between Nifedipine, Ritodrine and Magnesium Sulfate...

Table (2): Comparison between groups according to maternal heart rate

\begin{tabular}{|l|c|c|c|c|c|}
\hline Maternal heart rate & $\begin{array}{c}\text { Nifedipine } \\
(\boldsymbol{n = 5 0})\end{array}$ & $\begin{array}{c}\text { Magnesium } \\
\text { sulfate }(\boldsymbol{n = 5 0})\end{array}$ & $\begin{array}{c}\text { Ritodrine } \\
(\mathbf{n = 5 0})\end{array}$ & ANOVA & p-value \\
\hline Before treatment & $73-98$ & $74-94$ & $64-91$ & & \\
Range & $85.89 \pm 5.68$ & $83.85 \pm 5.03$ & $75.32 \pm 6.31$ & 8.811 & $<0.001^{* *}$ \\
Mean \pm SD & & & & & \\
\hline After treatment & $83-104$ & $77-104$ & $76-107$ & 0.097 & 0.923 \\
Range & $89.74 \pm 4.83$ & $88.3 \pm 6.46$ & $89.61 \pm 8.18$ & & \\
Mean \pm SD & $\mathbf{0 . 8 5 5}$ & $\mathbf{0 . 8 1 0}$ & $\mathbf{3 . 2 4 0}$ & & \\
\hline Mean difference & $\mathbf{0 . 0 5 7}$ & $\mathbf{0 . 0 5 4}$ & $<\mathbf{0 . 0 0 1} * *$ & & \\
\hline \#p-value &
\end{tabular}

Using: One Way ANOVA test; \#Paired Sample t-test, p-value $>0.05 \mathrm{NS}$; *p-value $<0.05 \mathrm{~S}$; **p-value $<0.001 \mathrm{HS}$

Table (2) shows statistically significant difference between groups according to maternal heart rate before treatment.

Also, significant difference between before and after treatment according to maternal heart rate in ritodrine.

Table (3): Comparison between groups according to fetal heart rate

\begin{tabular}{|l|c|c|c|c|l|}
\hline Fetal heart rate & $\begin{array}{c}\text { Nifedipine } \\
(\mathbf{n = 5 0})\end{array}$ & $\begin{array}{c}\text { Magnesium } \\
\text { sulfate }(\boldsymbol{n = 5 0})\end{array}$ & $\begin{array}{c}\text { Ritodrine } \\
(\mathbf{n = 5 0})\end{array}$ & ANOVA & p-value \\
\hline $\begin{array}{l}\text { Before treatment } \\
\text { Range }\end{array}$ & $120-163$ & $120-157$ & $116-156$ & & \\
Mean \pm SD & $140.92 \pm 9.59$ & $138.45 \pm 10.31$ & $134.14 \pm 12.34$ & 3.068 & $0.003^{*}$ \\
\hline After treatment & $127-168$ & $125-163$ & $131-170$ & & \\
Range & $145.21 \pm 10.87$ & $140.52 \pm 9.93$ & $151.26 \pm 11.09$ & 2.755 & $0.017^{*}$ \\
Mean \pm SD & $\mathbf{0 . 8 5 5}$ & $\mathbf{1 . 1 1}$ & $\mathbf{4 . 4 4 0}$ & & \\
\hline Mean difference & $\mathbf{0 . 0 5 7}$ & $\mathbf{0 . 0 7 4}$ & $<\mathbf{0 . 0 0 1} * *$ & & \\
\hline \#p-value & &
\end{tabular}

Using: One Way ANOVA test; \#Paired Sample t-test, p-value >0.05 NS; *p-value $<0.05 \mathrm{~S}$; **p-value $<0.001 \mathrm{HS}$

This table shows statistically significant difference between groups according to maternal heart rate before and after treatment. Also, significant difference between before and after treatment according to fetal heart rate in ritodrine group.

Table (4): Comparison between groups according to maternal complications

\begin{tabular}{|l|c|c|c|c|c|}
\hline Maternal complications & $\begin{array}{c}\text { Nifedipine } \\
(\boldsymbol{n}=\mathbf{5 0})\end{array}$ & $\begin{array}{c}\text { Magnesium } \\
\text { sulfate }(\boldsymbol{n = 5 0})\end{array}$ & $\begin{array}{c}\text { Ritodrine } \\
(\mathbf{n = 5 0})\end{array}$ & $\mathbf{x 2}$ & p-value \\
\hline Tachycardia, palpitation & $7(14.0 \%)$ & $15(30.0 \%)$ & $42(84.0 \%)$ & 8.291 & $<0.001 * *$ \\
\hline Dyspnea & $0(0.0 \%)$ & $0(0.0 \%)$ & $7(14.0 \%)$ & 4.623 & $0.027 *$ \\
\hline
\end{tabular}

Using: Chi-square test; *p-value <0.05 S; **p-value $<0.05 \mathrm{~S}$

This table shows statistically significant difference between groups according to maternal complications.

Table (5): Comparison between groups according to cassation of contractions after treatment

\begin{tabular}{|l|c|c|c|c|c|}
\hline $\begin{array}{l}\text { Cessation of contractions after } \\
\text { treatment }\end{array}$ & $\begin{array}{c}\text { Nifedipine } \\
(\boldsymbol{n}=\mathbf{5 0})\end{array}$ & $\begin{array}{c}\text { Magnesium } \\
\text { sulfate }(\boldsymbol{n}=\mathbf{5 0})\end{array}$ & $\begin{array}{c}\text { Ritodrine } \\
(\mathbf{n}=\mathbf{5 0})\end{array}$ & $\mathbf{x 2}$ & $\mathbf{p}$-value \\
\hline Cessation of contractions & $40(80 \%)$ & $35(70 \%)$ & $30(60 \%)$ & 3.267 & 0.286 \\
\hline
\end{tabular}

Using: Chi-square test; $p$-value >0.05 NS;

This table shows no statistically significant difference between groups according to cessation of contractions after treatment. 
Table (6): Comparison between groups according to fetal umbilical artery PI before and after treatment

\begin{tabular}{|l|c|c|c|c|l|}
\hline Fetal umbilical artery PI & $\begin{array}{c}\text { Nifedipine } \\
(\boldsymbol{n = 5 0})\end{array}$ & $\begin{array}{c}\text { Magnesium } \\
\text { sulfate }(\boldsymbol{n = 5 0})\end{array}$ & $\begin{array}{c}\text { Ritodrine } \\
(\mathbf{n = 5 0})\end{array}$ & ANOVA & p-value \\
\hline Before treatment & $0.9-1.3$ & $0.8-1.4$ & $0.9-1.3$ & \multirow{2}{*|}{3.922} & \multirow{2}{*}{$0.002^{*}$} \\
Range & $1.12 \pm 0.10$ & $1.02 \pm 0.15$ & $1.11 \pm 0.12$ & & \\
Mean \pm SD & & & & & \multirow{2}{*}{$0.018^{*}$} \\
\hline After treatment & $0.9-1.3$ & $0.8-1.4$ & $0.9-1.3$ & 2.398 & \\
Range & $1.11 \pm 0.10$ & $1.06 \pm 0.13$ & $1.12 \pm 0.12$ & & \\
Mean \pm SD & $\mathbf{0 . 7 8 3}$ & $\mathbf{3 . 1 3 2}$ & $\mathbf{1 . 1 8 4}$ & & \\
\hline Mean difference & $\mathbf{0 . 2 6 1}$ & $\mathbf{0 . 0 1 4}$ & $\mathbf{0 . 1 4 8}$ & & \\
\hline \#p-value & & &
\end{tabular}

Using: One Way ANOVA test; \#Paired Sample t-test

p-value $>0.05 \mathrm{NS} ;{ }^{*}$-value $<0.05 \mathrm{~S}$

This table shows statistically significant difference between groups according to fetal umbilical artery PI before and after treatment. Also, significant difference between before and after treatment according to fetal umbilical artery PI in magnesium sulfate group.

Table (7): Comparison between groups according to fetal middle cerebral artery PI

\begin{tabular}{|l|c|c|c|c|c|}
\hline $\begin{array}{l}\text { Fetal middle cerebral artery } \\
\text { PI }\end{array}$ & $\begin{array}{c}\text { Nifedipine } \\
(\boldsymbol{n = 5 0 )}\end{array}$ & $\begin{array}{c}\text { Magnesium } \\
\text { sulfate }(\boldsymbol{n = 5 0 )}\end{array}$ & $\begin{array}{c}\text { Ritodrine } \\
(\mathbf{n = 5 0})\end{array}$ & ANOVA & p-value \\
\hline Before treatment & $1.16-1.5$ & $1.2-1.7$ & $1.1-1.6$ & & \\
Range & $1.28 \pm 0.08$ & $1.32 \pm 0.14$ & $1.35 \pm 0.12$ & 3.432 & $0.009^{*}$ \\
Mean \pm SD & & & & & \\
\hline After treatment & $1.15-1.5$ & $1.3-1.8$ & $1.1-1.6$ & \multirow{2}{*}{12.508} & $<0.001^{* *}$ \\
Range & $1.29 \pm 0.08$ & $1.54 \pm 0.13$ & $1.34 \pm 0.12$ & & \\
Mean \pm SD & $\mathbf{3 . 3 7 5}$ & $\mathbf{8 . 1 0 4}$ & $\mathbf{1 . 2 0 5}$ & & \\
\hline Mean difference & $\mathbf{0 . 0 2 5 *}$ & $<\mathbf{0 . 0 0 1 * *}$ & $\mathbf{0 . 2 4 1}$ & & \\
\hline \#p-value &
\end{tabular}

Using: One Way ANOVA test; \#Paired Sample t-test, p-value >0.05 NS; *p-value $<0.05 \mathrm{~S} ; * *$ p-value $<0.001 \mathrm{HS}$

This table shows statistically significant difference between groups according to fetal middle cerebral artery PI before and after treatment.

Also, significant difference between before and after treatment according to fetal middle cerebral artery PI in nifedipine and magnesium sulfate group.

Table (8): Comparison between groups according to cerebroplacental ratio

\begin{tabular}{|l|c|c|c|c|c|}
\hline Cerebroplacental ratio & $\begin{array}{c}\text { Nifedipine } \\
(\boldsymbol{n}=\mathbf{5 0})\end{array}$ & $\begin{array}{c}\text { Magnesium } \\
\text { sulfate }(\boldsymbol{n = 5 0 )}\end{array}$ & $\begin{array}{c}\text { Ritodrine } \\
(\mathbf{n = 5 0 )}\end{array}$ & ANOVA & p-value \\
\hline Before treatment & $1.04-1.37$ & $1.08-1.55$ & $1.08-1.44$ & \multirow{2}{*}{1.257} & 0.212 \\
Range & $1.14 \pm 0.95$ & $1.31 \pm 0.11$ & $1.22 \pm 0.08$ & & \\
Mean \pm SD & & & & & \\
\hline After treatment & $1.04-1.37$ & $1.25-1.77$ & $1.08-1.44$ & \multirow{2}{*}{14.758} & $<0.001^{* *}$ \\
Range & $1.13 \pm 0.09$ & $1.46 \pm 0.13$ & $1.21 \pm 0.07$ & & \\
Mean \pm SD & $\mathbf{1 . 1 6 2}$ & $\mathbf{4 . 8 8 0 4}$ & $\mathbf{1 . 3 9 5}$ & & \\
\hline Mean difference & $\mathbf{0 . 3 4 4}$ & $<\mathbf{0 . 0 0 1 * *}$ & $\mathbf{0 . 4 6 5}$ & & \\
\hline \#p-value &
\end{tabular}

Using: One Way ANOVA test; \#Paired Sample t-test

p-value >0.05 NS; **p-value <0.001 HS

This table shows statistically significant difference between groups according to cerebroplacental ratio after treatment. Also, significant difference between before and after treatment according to cerebroplacental ratio in magnesium sulfate group. 
A Comparative Study between Nifedipine, Ritodrine and Magnesium Sulfate...

Table (9): Comparison between groups according to bishop score

\begin{tabular}{|l|c|c|c|c|c|}
\hline \multicolumn{1}{|c|}{ Bishop score } & $\begin{array}{c}\text { Nifedipine } \\
(\boldsymbol{n}=50)\end{array}$ & $\begin{array}{c}\text { Magnesium } \\
\text { sulfate }(\boldsymbol{n = 5 0 )}\end{array}$ & $\begin{array}{c}\text { Ritodrine } \\
(\mathbf{n = 5 0 )}\end{array}$ & ANOVA & p-value \\
\hline Before treatment & $5-10 \mathrm{a}$ & $5-9 \mathrm{a}$ & $5-11 \mathrm{a}$ & \multirow{2}{*}{0.783} & 0.261 \\
$\begin{array}{l}\text { Range } \\
\text { Mean } \pm \text { SD }\end{array}$ & $6.55 \pm 2.36$ & $6.16 \pm 2.31$ & $6.93 \pm 2.42$ & & \\
\hline After treatment & $5-11 \mathrm{a}$ & $5-10 \mathrm{a}$ & $5-13 \mathrm{a}$ & \multirow{2}{*}{0.267} & 0.089 \\
$\begin{array}{l}\text { Range } \\
\text { Mean } \pm \text { SD }\end{array}$ & $6.93 \pm 2.31$ & $6.38 \pm 1.98$ & $7.48 \pm 2.64$ & & \\
\hline Mean difference & $\mathbf{0 . 3 8}$ & $\mathbf{0 . 2 2}$ & $\mathbf{0 . 5 5}$ & & \\
\hline \#p-value & $\mathbf{0 . 4 1 8}$ & $\mathbf{0 . 2 4 2}$ & $\mathbf{0 . 6 0 5}$ & & \\
\hline
\end{tabular}

Using: One Way ANOVA test; \#Paired Sample t-test, p-value >0.05 NS

This table shows no statistically significant difference between groups according to bishop score before and after treatment. Also, no statistically significant difference between before and after treatment according to bishop score.

Table (10): Comparison between groups according to need for incubation

\begin{tabular}{|l|c|c|c|c|c|}
\hline Need for incubation & $\begin{array}{c}\text { Nifedipine } \\
(\boldsymbol{n}=\mathbf{5 0})\end{array}$ & $\begin{array}{c}\text { Magnesium } \\
\text { sulfate }(\boldsymbol{n = 5 0})\end{array}$ & $\begin{array}{c}\text { Ritodrine } \\
(\mathbf{n = 5 0})\end{array}$ & \multirow{2}{*}{$\mathbf{2}$} & p-value \\
\cline { 1 - 4 } Yes & $35(70 \%)$ & $38(76 \%)$ & $40(80 \%)$ & \multirow{2}{*}{1.360} & 0.506 \\
\hline No & $15(30 \%)$ & $12(24 \%)$ & $10(20 \%)$ & \\
\hline
\end{tabular}

Using: Chi-square test; $p$-value >0.05 NS;

This table shows no statistically significant difference between groups according to need for incubation.

\section{DISCUSSION}

In the developed world, preterm birth (PTB) is without doubt a major problem in modern obstetrics; its prevalence is still rising in many industrialised countries ${ }^{(4)}$. According to the USA National Vital Statistics Reports, $11-12 \%$ of the 4 million neonates born each year are delivered before 37 weeks and $3.6 \%$ are delivered before 34 weeks ${ }^{(\mathbf{1 4})}$.

When comparing the mean maternal age it was found to be $26.44 \pm 5$ (17-38), $26.75 \pm 4.24$ (19-40), $27.81 \pm 6.47$ (18-37) years old for Nifedipine, Magnesium Sulphate and Ritodrine groups respectively. The difference in age between groups was insignificant ( $\mathrm{p}=0.223$ ).

The mean parity for the nifedipine group was $1.79 \pm 1.14(0-4)$, for the magnesium sulfate group $2.01 \pm 0.87(0-3)$ and for the ritodrine group it was $1.69 \pm 0.65(0-4)$. The pvalue for the three groups was $\mathrm{p}=0.421$, which is statistically non-significant. In addition, when we compared the three study groups, it was found that the mean number of previous preterm labors for the nifedipine group was $0.66 \pm 0.81(0-3)$, for the magnesium sulfate group $0.74 \pm 0.68(0-2)$, and for the ritodrine group it was $0.53 \pm 0.64(0-2)$. The $\mathrm{p}$ value for the three groups was $\mathrm{p}=0.126$, which is statistically non-significant.

The mean gestational age at admission for the women included in the nifedipine group was $31.96 \pm 1.52$ weeks, for the magnesium sulfate group the mean gestational age at admission was $32.06 \pm 1.64$ weeks, and for the ritodrine group it was $31.9 \pm 1.68$ weeks. When comparing the results of the three study groups, the p-value was found to be 0.221 , which is statistically non-significant.

These characteristics are not different from the study held by Abdellateef Department of Obstetrics \& Gynecology in University Hospitals of Tanta, Egypt, to assess the effect of Nifidipine on fetal and maternal circulation, the maternal age in their study ranged

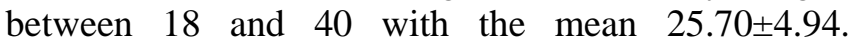
Gravidity ranged between 1 and 5 with the mean $2.44 \pm 1.20$. Parity ranged between $0-4$ with the mean $1.33 \pm 1.15$. Gestational age on admission ranged between 25 and 34 with the mean $30.33 \pm 2.54$. Fetal weight ranged between 780-2432 with the mean $1611.56 \pm 459.73^{(15)}$.

These characteristics also were nearly similar to results of a study conducted by Kamel $\boldsymbol{e t}$ al. ${ }^{(16)}$ who conducted a study among 90 patients attended and admitted from the Casualty Unit of the Obstetric Department In Elsayed Glal University and found that When comparing the mean maternal age it was found to be $25.67 \pm 5.268$ (16-39), $25.97 \pm 4.115$ (17-36), $27.97 \pm 6.278(19-42)$ years old for nifedipine, magnesium sulfate and ritodrine, respectively. When comparing those results the p-value was found to be 0.968 , which is statistically non-significant. When comparing the three study groups, it was found that the mean parity for the nifedipine group was $2.23 \pm 1.135$ (0-5), for the magnesium sulfate group $2.13 \pm 0.900$ (1-4) and for the ritodrine group it was $2.27 \pm 0.944$ (1-4). The pvalue for the three groups was 0.865 , which is statistically non-significant. In addition, when we compared the three study groups, it was found that 
the mean number of previous preterm labors for the nifedipine group was $0.63 \pm 0.765(0-3)$, for the magnesium sulfate group $0.70 \pm 0.750(0-2)$, and for the ritodrine group it was $0.50 \pm 0.63(0-2)$. The pvalue for the three groups was 0.549 , which is statistically non-significant ${ }^{\left({ }^{16)}\right.}$.

The mean gestational age at admission for the women included in the nifedipine group was $31.03 \pm$ 1.474 weeks, for the magnesium sulfate group the mean gestational age at admission was $31.13 \pm 1.592$ weeks, and for the ritodrine group it was $30.97 \pm 1.629$ weeks. When comparing the results of the three study groups, the p-value was found to be 0.918 , which is statistically nonsignificant ${ }^{(\mathbf{1 6})}$.

Also these characteristics were not much different from results of Conde-Agudelo $\boldsymbol{e t}$ al. ${ }^{(17)}$ study that was conducted on 80 patients divided into two groups to compare the efficacy of nifedipine and ritodrine in prolonging pregnancy beyond 48 hours, 1 week and 36 weeks. The mean maternal age in this study was $26.2 \pm 6.5$ years for the ritodrine group while it was $26.9 \pm 6.1$ years for the nifedipine group. The mean gestational age on admission was $32.1 \pm 2.1$ weeks for ritodrine group and $32.2 \pm 2.2$ weeks for nifedipine group. However, the parity for both groups ranged from $0-3$, which is logically less than that in our study due to the increased parity in the developing countries as Egypt more than that in the developed countries as Ireland where the study was held (17).

Most of the deliveries in the current study were by caesarean sections (80\%) for Nifidipine group, $84 \%$ for Magnesium sulfate group and $78 \%$ for ritodrine group ; there was no significant differences between groups regarding mode of delivery $(p=0.291)$. The high rate of caesarian section although insignificant, may reflect the claims that reduces the chances of fetal or neonatal death and birth trauma. However; Malloy (18) found no evidence that caesarean section can be protective for preterm neonates, especially for very low birthweight infants (less than $1500 \mathrm{~g}$ ); primary caesarean section may in fact increase risk of neonatal mortality and morbidity, such as pulmonary hypoplasia, necrotizing enterocolitis or sepsis.

Moreover; Caesarean section is known to be associated with an increased risk of respiratory morbidity in neonates, because hormonal and physiological changes associated with labour are necessary for lung maturation in neonates. On the other hand, found a trend towards reduced neonatal mortality rate in preterm (before 32 weeks) or very low weight (less than $1500 \mathrm{~g}$ ) babies with breech presentation born by caesarean section compared with vaginal delivery ${ }^{(\mathbf{1 9})}$.

The mean apgar score was $4.56 \pm 0.64$ for Nifedipine group, $4.43 \pm 0.62$ in Magnesium sulfate group and $4.14 \pm 0.58$ in Ritodrine group, the difference between groups was in significant $(\mathrm{p}=0.139)$. While the mean birth weight was 1783.9 \pm 237.1 ;
$1718.5 \pm 245.9 \quad 1650.9 \pm 254.8 ; \quad$ for Nifedipine, Magnesium sulfate and Ritodrine groups respectively. The difference between groups in birth weight was also non-significant $(\mathrm{p}=0.152)$

This was consistent with Lyell et al. (20), who compared fetal adverse effects resulting from administration of Nifedipine versus Magnesium sulfate; they found that mean birth weight was $2,55 \pm 802$ grams among Nifedipine group, and 2,65 \pm 698 grams among Magnesium sulfate ; this difference in birth weight was insignificant $(\mathrm{p}=0.38)$.

In our study, when we observed the cardiovascular changes that occurred after administration of the three drugs, it showed that all of the three drugs caused an increase in the maternal heart rate after their administration. However, it reached a statistically significant value only in the ritodrine group. In the ritodrine group, the mean maternal heart rate was $75.32 \pm 6.31 \mathrm{bpm}$ before ritodrine administration and reached $89.61 \pm 8.18 \mathrm{bpm}$ after its administration. The p-value was $<0.001$ denoting a statistically significant value. While in the nifedipine group, the mean maternal heart rate was $85.89 \pm 5.68 \mathrm{bpm}$ before treatment and reached $89.74 \pm 4.83 \mathrm{bpm}$ after treatment with p-value 0.057 denoting a statistically nonsignificant value. In addition, in the magnesium sulfate group the maternal heart rate changed from $83.85 \pm 5.03 \mathrm{bpm}$ to $88.3 \pm 6.46 \mathrm{bpm}$ with p-value 0.054 , which is statistically non-significant. Previous study suggested that nifidipine causes decrease in vascular resistance and $\mathrm{BP}$, which lead to both a compensatory rise in HR as well as to an improved ventricular emptying with increased $\mathrm{SV}$ and $\mathrm{CO}$ and decreased ventricular filling pressure ${ }^{(\mathbf{2 1})}$.

These results came in agreement with Kamel $\boldsymbol{e t}$ al. (16) study, which showed that all of the three drugs caused an increase in the maternal heart rate after their administration. However, it reached a statistically significant value only in the ritodrine group. In the ritodrine group, the mean maternal heart rate was $76.23 \pm 6.383 \mathrm{bpm}$ before ritodrine administration and reached $90.70 \pm 8.276 \mathrm{bpm}$ after its administration. The p-value was 0.000 denoting a statistically significant value. While in the nifedipine group, the mean maternal heart rate was $86.93 \pm 5.747 \mathrm{bpm}$ before treatment and reached $90.83 \pm 4.893 \mathrm{bpm}$ after treatment with $\mathrm{p}$-value 0.061 denoting a statistically non-significant value. In addition, in the magnesium sulfate group the maternal heart rate changed from $84.87 \pm 5.090 \mathrm{bpm}$ to $89.37 \pm 6.542 \mathrm{bpm}$ with $\mathrm{p}$-value 0.058 , which is statistically non-significant ${ }^{(\mathbf{1 6})}$.

There was a statistical difference in the maternal heart rate between the three groups before administration of the drugs ( $p$-value <0.001). While, after their administration; no statistically significant difference was noted between groups at all-time points of treatment ( $\mathrm{p}$-value $=0.923$ ). This was in disagreement with Kamel $\boldsymbol{e t}$ al. ${ }^{(16)}$ who found no 
statistical difference in the maternal heart rate between the three groups before administration of the drugs (pvalue $=0.172$ ). While, after their administration a statistically significant difference was noted between ritodrine group and the other two groups at all-time points of treatment ( $\mathrm{p}$-value $=0.000$ ).

The current study showed that fetal heart rate increased from $134.14 \pm 12.34 \mathrm{bpm}$ to $151.26 \pm 11.09$ bpm ritodrine group ( $\mathrm{p}$-value $<0.001$ ), and this was statistically significant. While in the nifedipine group, the fetal heart rate increased from $140.92 \pm 9.59 \mathrm{bpm}$ to $145.21 \pm 10.87$ bpm (p-value 0.057, statistically nonsignificant). Besides, in the magnesium sulfate group the fetal heart rate slightly changed from $138.45 \pm 10.31 \mathrm{bpm}$ to $140.52 \pm 9.93 \mathrm{bpm}$ (p-value 0.074 , statistically non-significant). Moreover, there was a significant difference between the three groups in fetal heart rate $(\mathrm{p}=0.003)$ and after treatment $(\mathrm{p}=0.017)$.

This was in agreement Kamel et al. (16); who compared the effect of each tocolytic drug on fetal heart rate, separately; and found that fetal heart rate was significantly greater in the ritodrine group at all points during treatment.

However; this was in disagreement with previous literature that showed no significant difference in fetal heart rate after tocolytic administration ${ }^{(22)}$.

Fetal heart rate increased from $135.77 \pm 12.492$ bpm to $153.1 \pm 11.241$ bpm (p-value 0.000, statistically significant). While in the nifedipine group, the fetal heart rate increased from $142.63 \pm 9.704 \mathrm{bpm}$ to $146.97 \pm 10.997 \mathrm{bpm}$ (p-value 0.061 , statistically non-significant). Besides, in the magnesium sulfate group the fetal heart rate slightly changed from 140.13 \pm 10.438 bpm $^{(\mathbf{1 6})}$.

All significant differences in the maternal and fetal hemodynamic parameters between the three groups were consistent with the work done by Black $\boldsymbol{e t}$ al. ${ }^{(23)}$ who examined the maternal and fetal cardiovascular effects of GTN compared with ritodrine for acute tocolysis. Sixty women with preterm labor were enrolled in this study. Once randomized, the women received transdermal GTN or intravenous ritodrine according to the guidelines of the RCOG. Measurements of the maternal pulse, blood pressure, and fetal heart rate were recorded for up to 24 hours and compared over the treatment course. The mean maternal heart rate was lower in the GTN group $(p<0.01)$, the mean fetal heart rate was significantly lower during GTN treatment $(\mathrm{p}=0.008)$. Ritodrine had a significantly hypotensive effect on mean arterial pressure. Mean arterial pressure was not significantly different over the treatment course with GTN ${ }^{(23)}$.

The current study results showed that Ritodrine group participants had significantly highest rate of maternal complications in the form of Tachycardia and palpitation compared to other two groups (84\% of Ritodrine group, compared to $30 \%$ and $14 \%$ in Magnesium sulfate and Nifedipine respectively, p- value $<0.001$ ). Dyspnea occurred in $14 \%$ of Ritodrine group participants, while no dyspnea was observed among mothers in Magnesium sulfate and Nifedipine group ; this difference between groups was significant $(\mathrm{p}=0.027)$.

This was in agreement with Haas et al. ${ }^{(21)}$ and Alfirevic ${ }^{(24)}$, in their metanalysis, who stated that Calcium channel blockers, including Nifedipine had only a $15 \%$ probability of being ranked in the top three drug classes for maternal side effects; Whereas beta mimetics (including Ritodrine and Magnesium sulfate), showed statistically significant harmful effects on mothers ${ }^{(21)}$.

Moreover, Nifedipine was associated with significantly fewer mild and severe maternal adverse effects, compared to Magnesium sulfate ${ }^{(20)}$.

In the present study, there was cessation of contractions in the three study groups after administration of the drugs, which was more evident in nifedipine group (80\%).

When comparing the presence of contractions among the three groups with each other after treatment; it was found that the difference had no significant value ( $\mathrm{P}$ value 0.286 ). This meant that all of the three drugs caused cessation of contractions nearly with the same efficacy.

Similar findings were observed in the study by Kamel et al. (16). In which there was cessation of contractions in the three study groups after administration of the drugs, which was more evident in nifedipine group $(80 \%)$. And also no significant difference was noted between the three groups, when comparing the presence of contractions among the three groups with each other after treatment; (P value 0.24).

In our study, when we observed the Doppler changes on fetal umbilical and middle cerebral arteries that occurred after administration of the three drugs, it showed increase in umbilical artery PI after treatment in the magnesium sulfate group only, which was statistically significant $(\mathrm{P}$ value $=0.014)$. In the ritodrine group, the mean umbilical PI was $1.11 \pm 0.12$ before ritodrine administration and reached $1.12 \pm 0.12$ after its administration. The $p$-value was 0.148 denoting a statistically non-significant value. While in the nifedipine group, the mean umbilical PI was $1.12 \pm 0.10$ before treatment and reached $1.11 \pm 0.10$ after treatment with p-value 0.281 denoting a statistically non-significant value.

This was in agreement with Kamel et al. ${ }^{(16)}$, who found significant increase in umbilical artery PI after treatment in the magnesium sulfate group only $(\mathrm{P}$ value $=0.016)$. Whereas no significant differences in mean umbilical PI were observed before and after treatment in case of ritodrine ( $\mathrm{p}$-value $=0.161)$; nor in case of treatment with nifedipine ( $\mathrm{p}$-value $=0.281)$.

Guclu et al. ${ }^{(22)}$ were the first to study fetal Doppler indices during 48 hours of nifedipine tocolysis. They found no changes in umbilical artery PI during 
treatment, although they did find decreased uterine artery PI and middle cerebral artery PI at 24 hours and 48 hours of treatment.

The mean PI of fetal middle cerebral artery showed significant differences between the three groups before treatment $(\mathrm{p}=0.009)$, and after treatment $(\mathrm{p}<0.001)$.

Also there was a significant difference before and after treatment in Nifedipine group $(\mathrm{p}=0.025)$ and in magnesium sulfate group $(\mathrm{p}<0.001)$.

These results were in agreement with Lima et al 2009 and Kamel et al. (16); whose studies found significant increase in middle cerebral artery PI after treatment in magnesium sulfate group with a $\mathrm{P}$ value 0.000 and showed statistically significant decrease in nifedipine group with a $\mathrm{P}$ value 0.027 and the decrease was within clinically acceptable levels.

In the nifedipine group, the mean MCA PI was $1.3 \pm$ 0.082 before nifedipine administration and reached 1.29 \pm 0.081 after its administration. The p-value was 0.027 denoting a statistically significant significant value. While in the ritodrine group, $\mathrm{p}$ - value 0.26 denoting a statistically non-significant value.

Cerebroplacental ratio before treatment showed no statistical difference between the three groups in the current study $(\mathrm{p}=0.212)$; while there was a significant difference between the groups $(\mathrm{p}<0.001)$. Magnesium sulfate group showed a significant difference in cerebro-placental ratio before and after treatment $(\mathrm{p}<0.001)$.

Kamel et al. (16) in their study 2018; when comparing the cerebroplacental ratio before and after treatment in the three groups; found similar results; with significant increase in cerebroplacental ratio after treatment in the magnesium sulfate group with $\mathrm{P}$ value $=0.000$ which, was statistically significant. In the nifedipine group the mean cerebroplacental ratio was1.15 \pm 0.96 before nifedipine administration and reached $1.148 \pm 0.091$ after its administration. The pvalue was 0.370 denoting a statistically nonsignificant value. While in the ritodrine group, the mean cerebroplacental ratio was $1.23 \pm 0.079$ before treatment and reached $1.22 \pm 0.081$ after treatment with p-value 0.5 denoting a statistically non-significant value (16). Meanwhile, Guclu et al. ${ }^{(22)}$ in their study, stated that Nifedipine maintenance was associated with a significant fall in the cerebroplacental Doppler ratio was maintained beyond $24 \mathrm{~h}$.

The mean bishop score was calculated before and after treatment. For the Nifedipine group it was $6.55 \pm 2.36$ before treatment and $6.93 \pm 2.31$ after treatment; and the difference was insignificant $(\mathrm{p}=$ 0.418 ). For the Magnesium sulfate group it was $6.16 \pm 2.31$ before treatment and $6.38 \pm 1.98$ after treatment ( $\mathrm{p}=0.242$; no significant difference). And for Ritodrine group it was $6.93 \pm 2.42$ before treatment and $7.48 \pm 2.64$ after treatment; this difference was also non significant $(\mathrm{p}=0.605)$. When comparing the three results, the $\mathrm{p}$-value for the three groups was 0.261 before treatment; and 0.089 after treatment; which is statistically non-significant.

The insignificant difference between groups before treatment was in agreement with Kamel $\boldsymbol{e t}$ al. ${ }^{(\mathbf{1 6})}$ who found insignificant differences between the three groups in admission with $\mathrm{p}$ value was 0.045 .

The current study results showed that the majority of newly born needed incubation after birth; indicating high rate of neonatal morbidity. The highest proportion was among Ritrodrine group (80\%), followed by Magnesium sulfate group (76 \%) and lowest was among Nifedipine group (70\%). There wasn't a significant difference between the three groups $(p=0.506)$. This was in partial agreement with results of an open randomized controlled trial conducted to assess neonatal effects of oral nifedipine $(\mathrm{n}=95)$ and intravenous Ritodrine $(\mathrm{n}=90)$; that Nifedipine was found to be associated with a lower incidence of neonatal morbidity (neonatal intensive care unit admissions, intracranial hemorrhage, respiratory distress syndrome, and neonatal jaundice); similar to the current study results; however this difference was significant $(\mathrm{p}<0.05)^{(25)}$.

Similarly, while comparing adverse effects in neonates as an outcome of Nifidepine versus Magnesium sulfate administration; neonatal morbidities were similar between groups, but neonatal intensive care admission rate was higher in newborns in the magnesium sulfate group (52\%) compared to Nifedipine (37\%), and this result was significant $(\mathrm{p}=0.04)^{(20)}$. Moreover, when comparing side effects of Nifedipine versus Ritodrene; the number of admissions to the neonatal intensive care unit (NICU) in the nifedipine group was significantly lower than in the ritodrine group (68.4 versus $82.1 \%, \mathrm{P}=.04)^{(21)}$.

Several literature demonstrated that nifedipine treatment did not influence either fetal or uteroplacental circulation ${ }^{(26)}$. It is generally considered to be safe for both mother and fetus and it reduces respiratory distress syndrome, necrotizing enter colitis and intraventricular hemorrhages. The direct maternal adverse effects are related to the vasodilatation caused by nifedipine and are primarily headache and facial flushes. Generally, these complaints disappear within 24 hours. On the other side, side effects were much more in the magnesium sulfate and ritodrine group than the nifedipine group $(\mathrm{p}<.05)^{(27)}$.

\section{CONCLUSION}

There was no overall difference between nifedipine, magnesium sulfate and ritodrine, in their efficacy as tocolytic for preterm labor. However, Nifedipine had fewer maternal side effects followed by magnesium sulfate than ritodrine. Irrespective of their tocolytic effects, magnesium sulfate has the most significant effect on Doppler study. 


\section{REFERENCES}

1. Crowther CA, Brown J, McKinlay CJD, Middleton $P$ (2014): Magnesium sulphate for preventing preterm birthin threatened preterm labour. Cochrane Database of Systematic Reviews Issue 8 . https://www.cochrane.org/CD001060/PREG_magnesiu $\mathrm{m}$-sulphate-for-preventing-preterm-birth-in-threatenedpreterm-labour

3. Goldenberg R, Andrews WW, Hauth JC (2002): Choriodecidual infection and preterm birth. Nutr Rev., 60(5):19-25.

4. Flenady V, Reinebrant HE, Liley HG, Tambimuttu E G, Papatsonis DN (2014): Oxytocin receptor antagonists for inhibiting preterm labour. Cochrane Database of Systematic Reviews, (6): 333-343.

5. Grimes DA, Nanda $K$ (2006): Magnesium sulfate tocolysis: time to quit. Obstetrics \& Gynecology, 108(4):986-9.

6. Elliott JP, Morrison JC, Bofill JA (2016): Risks and benefits of magnesium sulfate tocolysis in preterm labor (PTL). AIMS Public Health, 3(2):348-352.

7. Berger V, Davis A, Chock V (2016): perinatal neuroprotection for extremely preterm infants. Am J Perinatol., 33:290-296.

8. Bain ES, Middleton PF, Crowther CA (2013): Maternal adverse effects of different antenatal magnesium sulphate regimens for improving maternal and infant outcomes: a systematic review. BMC Pregnancy and Childbirth, 13(1):195-202.

9. Crowther CA, Hiller JE, Doyle LW, Haslam RR (2003): Australasian Collaborative Trial of Magnesium Sulphate (ACTOMg SO4) Collaborative Group. Effect of magnesium sulfate given for neuroprotection before preterm birth: a randomized controlled trial. JAMA., 290:2669-76.

10. Sayin NC, Arda S, Varol FG, Süt N (2010): The effects of ritodrine and magnesium sulfate on maternal and fetal Doppler blood flow patterns in women with preterm labor. European Journal of Obstetrics \& Gynecology and Reproductive Biology, 152(1):50-4.

11. Figueira C, Surita F, Dertkigil M et al. (2016): Fetal Homodynamic Parameters in Low Risk Pregnancies: Doppler Velocimetry of Uterine, Umbilical, and Middle Cerebral Artery. https://www.hindawi.com/journals/tswj/2016/1693704/

12. Srikumar S, Debnath J, Ravikumar R, Bandhu HC, Maurya VK (2017): Doppler indices of the umbilical and fetal middle cerebral artery at 18-40 weeks of normal gestation: A pilot study. Medical Journal Armed Forces India, 73(3):232-41.

13. King JF, Flenady V, Papatsonis D et al. (2003): Calcium channel blockers for inhibiting preterm labor.A systemic review of the evidence and a protocol for administration of nifedipine. Aust NZJ Obstet Gynaecol., 43:192-195.

14. Green NS, Damus K, Simpson JL, Iams J, Reece EA, Hobel CJ (2005): Research agenda for preterm birth: recommendations from the March of Dimes. American Journal of Obstetrics and Gynecology, 193(3): 626-635.

15. Abdellateef SS, El Shorbagy SH, Hagras AM, Ghareeb AE (2018): Assessment of maternal nifedipine as a tocolytic agent on the Doppler indices of uterine and fetal umbilical and middle cerebral arteries. Gynecol Obstet Res Open J., 4(2): 44-49.

16. Kamel HE, HosamEldin NM and Soltan MA (2018): Comparative Study between the Effect of Nifedipine, Ritodrine and Magnesium Sulphate Therapy on Doppler Indices of Fetal Umbilical and Middle Cerebral Arteries in Patients with Preterm Labour. Egyptian Journal of Hospital Medicine, 74(2): 218-223.

17. Conde-Agudelo A, Romero R, Kusanovic JP (2011): Nifedipine in the management of preterm labor: a systematic review and metaanalysis. Am J Obstet Gynecol., 204(2):1-20.

18. Malloy M (2009): Malloy MH. Impact of cesarean section on intermediate and late preterm births: United States, 2000-2003. Birth, 36(1):26-33.

19. Hansen $T$, Hansen AK, Wisborg $K$, Uldbjerg $N$, Henriksen TB (2008): Risk of respiratory morbidity in term infants delivered by elective caesarean section: cohort study. BMJ., 336(7635):85-7.

2. Sentilhes L, Sénat MV, Ancel PY et al. (2017): Prevention of spontaneous preterm birth: Guidelines for clinical practice from the French College of Gynaecologists and Obstetricians (CNGOF). Eur J Obstet Gynecol Reprod Biol., 210:217-24.

20. Lyell DJ, Pullen K, Campbell L, Ching S, Druzin ML, Chitkara U, Burrs D, Caughey AB, El-Sayed YY (2007): Magnesium sulfate compared with nifedipine for acute tocolysis of preterm labor: a randomized controlled trial. Obstet Gynecol., 110 (1):61-67.

21. Haas DM, Quinney SK, Clay JM, Renbarger JL, Hebert MF, Clark S (2013): Nifedipine pharmacokinetics are influenced by CYP3A5 genotype when used as a preterm labor tocolytic. American Journal of Perinatology, 30(04): 275-282.

22. Guclu S, Saygili U, Dogan E, Demir N, Baschat AA (2004): The short- term effect of nifedipine tocolysis on placental, fetal cerebral and atrioventricular Doppler waveforms. Ultrasound in Obstetrics and Gynecology, 24(7): 761-765.

23. Black RS, Lees C, Thompson C et al. (1999): Maternal and fetal cardiovascular effects of transdermal glyceryl trinitrate and intravenous ritodrine. Obstet Gynecol., 94(4):572-6.

24. Alfirevic $Z$ (2012): Tocolytics: do they actually work?. BMJ., 345:e6531.

25. Nassar AH, Aoun J and Usta IM (2011): Calcium channel blockers for the management of preterm birth: a review. American Journal of Perinatology, 28(01): 057066.

26. Nikbakht R, Moghadam MT and Ghane'ee H (2014): Nifedipine compared to magnesium sulfate for treating preterm labor: A randomized clinical trial. Iranian Journal of Reproductive Medicine, 12(2): 145.

27. Kim JH, Ahn KH, Kim JY, Jeong YJ and Cho SN (2001): A comparison for efficacy and safety of magnesium sulfate (Magrose): ritodrine hydrochloride (Yutopar) and nifedipine (Adalat) in the management of preterm labor. Korean Journal of Obstetrics and Gynecology, 44(6): 1165-1170. 